\title{
Chapter 13 \\ Ageism in the Health Care System: \\ Providers, Patients, and Systems
}

\author{
Mary F. Wyman, Sharon Shiovitz-Ezra, and Jürgen Bengel
}

\subsection{Introduction}

According to the World Health Organization, 23.1\% of the global burden of disease (measured in disability-adjusted life years, or DALYs) can be attributed to illness in persons aged 60 years and older (World Health Organization 2008). Throughout much of the world, the ongoing demographic shifts in the population has resulted in the steady growth of the older adult patient group in the health care system (Thiem et al. 2011). Further, despite general agreement that older adults do not access medical care as frequently as needed (European Commission 2008), per-person health care spending is much higher for older adults than for younger adults. In the USA, for example, those over 65 years make up less than $15 \%$ of the population but account for over $36 \%$ of total health care costs (Jecker 2013). In Germany, older citizens with multiple medical conditions comprise the $5 \%$ of health care users responsible for over $30 \%$ of prescription drug costs (Kuhlmey et al. 2003). Within

M. F. Wyman $(\bowtie)$

W. S. Middleton Memorial Veterans Hospital and University of Wisconsin School of

Medicine \& Public Health, Madison, WI, USA

University of Freiburg, Freiburg im Breisgau, Germany

e-mail:mfwyman@wisc.edu

S. Shiovitz-Ezra

The Paul Baerwald School of Social Work and Social Welfare, The Hebrew University of Jerusalem, Jerusalem, Israel

The Israeli Gerontological Data Center (IGDC), the Hebrew University of Jerusalem, Jerusalem, Israel

e-mail: sharon.shiovitz@mail.huji.ac.il

J. Bengel

University of Freiburg, Freiburg im Breisgau, Germany

e-mail: bengel@psychologie.uni-freiburg.de

L. Ayalon, C. Tesch-Römer (eds.), Contemporary Perspectives on Ageism, International Perspectives on Aging 19,

https://doi.org/10.1007/978-3-319-73820-8_13 
the National Health Service in the United Kingdom, older persons make up twothirds of all care consumers (United Kingdom Department of Health 2001). The growing group of "old-old" patients (those aged 85+) with complex medical needs accounts for an over-proportionate amount of health care spending in Europe (Konig et al. 2013; Kuhlmey et al. 2003; Lehnert et al. 2011).

Thus, older adults represent a highly significant group of users of the health care system, and their care has a major impact on health care costs. Additionally, being a regular consumer of medical services is a significant part of daily life for many older adults around the globe. As the "third age" has been extended through longer average lifespans, so too are older persons living with more chronic and acute health problems and relying on care through the health system to maintain functioning and prolong life.

Despite their importance as health care consumers, a recent report issued by the Institute of Medicine (Institute of Medicine 2008) argues that negative attitudes towards older adults persist in the health care community, across professional disciplines, and across care settings. Ageist stereotypes, prejudice, and discrimination are potential barriers for health equality, in terms of the quantity and quality of care provided to older patients and their health-related outcomes (Courtney et al. 2000; Robb et al. 2002). Ageism is similar to other known forms of discrimination such as gender-based discrimination (sexism) and ethnicity-based discrimination (racism). Whereas sexism and racism rely on biological attributes which are life-long and usually cannot be changed, however, the bias against older persons will affect all of us who live long enough (Levy and Banaji 2002; Palmore 2001). In the words of Robert Butler (1975), who coined the term, ageism results in older persons being "categorized as senile, rigid, and old-fashioned in morality and skills. Ageism allows those of us who are younger to see old people as 'different.' We subtly cease to identify with them as human beings, which enables us to feel more comfortable about our neglect and dislike of them" (p. 894). More recently, Iversen and colleagues proposed a comprehensive description of ageism with the goal of further refining the operationalization and conceptualization of the construct in research (Iversen et al. 2009). This definition encompasses dimensional concepts already well-established in social psychology: (1) cognitive dimension (stereotypes); (2) emotional dimension (prejudice); and (3) behavioral dimension (discrimination). This dimensional approach reflects the fact that, on the basis of age-based categorizations or stereotyping, people can have biased thoughts or feelings about older people and/or engage in discriminating behavior toward older people. These authors go on to state that ageism can be conscious (explicit) or unconscious (implicit), and can be expressed at three levels: interpersonally, among individuals (the micro level); intra-group, that is, within social networks (the meso level); and through institutional policies or cultural traditions (the macro level).

There are a number of theories which attempt to explain the origin of ageism. Two theories in particular are highly relevant to healthcare providers and have received considerable attention (Nelson 2005). The functional approach theory (Snyder and Miene 1994) views stereotyping as serving an important function in the cognitive realm (e.g., using rapid categorization to enhance efficiency) and social realm (e.g., identifying oneself with the social in-group). Categorization may serve 
an important function for clinical decision making. This theory, along with the Terror Management Theory (Greenberg et al. 2002), also emphasizes that a negative bias against older persons acts as an ego-protective mechanism, used to deny and distance ourselves from the negative aspects of old age. According to the Terror Management Theory, ageism is closely associated with a human desire to dissociate one's self from reminders of one's own inevitable death, leading to attitudes and behaviors that reinforce separation from individuals or groups that arouse fear of death, such as older persons (Greenberg et al. 2002). As old age is also closely associated with deteriorating health, diminishing functional abilities, and lower social status, which leads to low self-esteem (Martens et al. 2005), the adoption of ageist attitudes and behavior serves to enhance our identification with our social in-group, and to help us dissociate ourselves from reminders of our own future decline.

One can understand intuitively that anxiety regarding severe illness or death may be highly relevant within the health care setting. Health care professionals often have prolonged exposure to the most infirm, ill, and senile older adults, which may bias their perspective and intensify their willingness to disassociate from the older population through ageist practices (Kearney et al. 2000; Lookinland and Anson 1995; Palmore 1990). There is some empirical support for the association of more negative attitudes with higher anxiety about ageing among health care workers (Liu et al. 2015).

This chapter presents a focused look at age bias as it is manifested in the health care setting. Of note, in this chapter we concentrate on the medical care setting, whereas the chapter by Bodner and colleagues (2018; Chap. 15) in this volume explores ageism within the mental health care system, and the chapter by Fialova and colleagues (2018; Chap. 14) is focused on pharmacological treatments and ageism. We leave a detailed critique of research methodology in this area to Buttigieg and colleagues (2018; Chap. 29) in this volume. Within the micro level (provider to patient), we review research examining attitudes toward, beliefs about, and clinical practices with older patients. On the macro (policy and cultural) level, we examine geriatric care and reimbursement policy across countries, and look at the very limited presence of older patients in the development of new therapies and within health care training curricula. We briefly consider the challenge of distinguishing between discrimination based on age and reasoned, conservative care provided by clinicians to their older patients. Finally, we offer conclusions and recommendations for the future.

\subsection{Providers and Patients: Ageism at the Micro Level}

\subsubsection{Ageist Attitudes and Practices Among Health Care Professionals}

There is an ample body of literature documenting negative attitudes towards older patients among health care providers, though conclusions are limited due to the use of a wide range of measurement approaches (for example, a number of different instruments have been used to assess "ageist" attitudes). Lookinland and Anson 
(1995) reported that registered nurses, as well as high school students interested in becoming nurses, exhibited negative attitudes and stereotypical beliefs related to ageing and older adults, with the latter exhibiting the least favorable attitudes and views. One study found that nurses tend to assign a lower status to geriatric nursing compared to other practice areas (Wells et al. 2004) and in another study, nursing trainees indicated a general lack of interest in working with older adults (Hayes et al. 2006). However, a recent survey study (Boswell 2012) among health care students in an undergraduate course on ageing found no clear tendency toward more negative or positive attitudes.

Several review articles have focused on attitudes toward older adults among health care providers. Attitudes among physicians are complex and mixed (Meisner 2012), with some studies of this population demonstrating clearly negative evaluations of older adults and others more neutral or positive evaluations. This also appears to be true of studies of attitudes toward ageing among nurses (Liu et al. 2013). There may be shifts in attitudes among health care professionals over time: results of a recent systematic review suggested an improvement in medical students and physician attitudes since 2000, but a decrease from positive to more neutral attitudes towards older people among nurses and nurse trainees (Liu et al. 2012). A review of studies examining nurses working in the acute health care setting revealed primarily positive attitudes toward ageing, though some studies reported negative attitudes, mainly reflecting a negative emotional evaluation of patients (Courtney et al. 2000). Most concerning, these authors found evidence in their review for an association between negative attitudes and clinical practice decisions.

Discrimination based on age may be reflected in clinical practice and decisionmaking among health care providers. Studies using both hypothetical decisionmaking scenarios and patient record review have demonstrated age-based disparities in diagnostic procedures as well as in the types of treatment offered to patients. These reports emerge from various fields of medicine including cardiology (Bowling 1999), oncology (Kagan 2008), and stroke treatment (Hadbavna and O'Neill 2013). For example, a study conducted in England revealed that though the prevalence of breast cancer is considerably higher among older women compared to younger women (40\% of cases are over age 70 ), only $11 \%$ of these older women had received breast cancer screening examinations by their physician. Moreover, only $7 \%$ of the physicians participating in that study conducted breast examinations on older female patients on a routine basis (Haigney et al. 1997). A study conducted among physicians and second-year medical students indicated an age bias in beliefs regarding follow-up treatment for patients undergoing surgery for breast cancer (Madan et al. 2001, 2006). Younger patients described in vignettes were significantly more likely to be recommended for breast-conservation therapy, whereas a higher percentage of older patients were recommended for modified radical mastectomy. This study also found that younger patients were more likely to be recommended for breast reconstruction procedures following mastectomy. Among lung cancer patients in the U.K., the likelihood of being referred for surgery was lower for older people, despite clinical evidence that post-operative recovery outcomes are not dependent on age (Peake et al. 2003). The same trend has been found in cardiology: 
coronary heart disease in older patients, specifically older women, is more likely to be treated pharmacologically rather than surgically (Wenger 1997). A U.S. study found evidence of age-related under-treatment of heart attacks relative to national treatment guidelines, with older patients less likely to receive standard diagnostic procedures and recommended treatments (McLaughlin et al. 1996).

\subsubsection{Ageist Communication by Health Care Professionals}

Another aspect of age discrimination relates to the way health care providers communicate with older adults. A number of studies provide evidence that patronizing and ineffective communication can characterize discourse between providers and older patients (Ambady 2002). Overall, physicians involve older patients in medical decisions less frequently than they involve younger patients. Further, physicians tend to be less patient, less respectful, less involved, and less optimistic with older patients compared to younger patients (Greene et al. 1996). While there is certainly individual variability in patient preferences for the type of communication with a health care provider, there is no evidence that these attributes of interpersonal communication are preferred by older persons. Above and beyond the potentially negative emotional experience for older patients and family members in the face of a provider's "poor bedside manner," provider communication styles may have substantive negative health consequences for the patient (Nussbaum et al. 2005). For example, one research study analyzing videotaped encounters between a physical therapist and an older patient found that distancing and indifferent behaviors (e.g., not smiling; looking away from the client) were related to more negative short- and long-term cognitive and physical health outcomes for the patient (Ambady 2002).

In a study of nurses, the quality of communication with and care provided to older patients was found to be associated with attitudes toward ageing (CarisVerhallen et al. 1999). More negative nurse attitudes were related to shorter, more superficial, and more task-oriented conversations with older patients. The nurses tended to speak to the older patients in a patronizing tone and did not involve them in consultations or decisions. In a similar vein, McLafferty and Morrison (2004) found that nurses' negative attitudes towards older patients were reflected in low expectations for rehabilitation as well as in more detached treatment of the patients. In this study, nurses were less likely to use humor with their older patients, and were less likely to remember the names of older patients compared to younger patients. A recent qualitative study which compared physicians, nurses, and social workers in Israel found that exclusion of older patients from conversations about their own medical care characterized the interactional styles across disciplines. These health care professionals tended to either "bypass" the older patient by approaching younger family members, or to make clinical decisions without any meaningful patient input. In follow-up interviews, health care providers listed several primary reasons for this type of communication style: (1) lack of self-awareness of this pattern; (2) "choosing the way that is easiest" (i.e., it is simpler to have health care 
discussions with a younger family member rather than the older patient); and (3) the provider "not relating to the patient [as a person]" (Ben-Harush et al. 2016).

An operant-observational study conducted in a nursing home revealed yet another detrimental pattern of communication between staff and residents, termed the "dependency-support script" (Baltes et al. 1980). Findings showed that nursing assistants were more positively responsive to dependent behaviors than to expressions of independence, and reacted with a dependence-supporting response (i.e., praising residents for their acceptance of help). The authors asserted that this type of communication reinforces dependency and discourages independent behavior in older adults. This association was identified in the Ben-Harush et al. (2016) study as well, as described clearly in a quote by a social worker:

When an older person enters the hospital, there is a certain approach towards them that makes them more dependent. The patient can be a very independent person... and somehow the attitude of the personnel towards them makes them change...they immediately put a diaper on people who did not need a diaper before... Something about entering a hospital promotes a regression for every person, and for older adults the regression is even harsher. They put a diaper on so fast because they don't want to deal with it. Someone has to help these patients stand and walk them to the bathroom... there is no time... (Ben-Harush et al. 2016).

\subsubsection{Factors Associated with Ageism in the Medical Setting}

Factors Associated with Health Care Personnel A handful of studies have examined predictors of ageist attitudes among health care providers. Among nursing students and registered nurses in Sweden, younger age ( $<25$ years old) and male gender were associated with more negative attitudes toward ageing (Lookinland and Anson 1995; Soderhamn et al. 2001). These associations were confirmed in a study conducted among Greek nursing students; young age and male gender were associated with increased ageism, as measured by more negative attitudes towards older adults and less accurate knowledge about ageing (Lambrinou et al. 2009). Similarly, characteristics of physicians that were associated with more positive attitudes towards older people included being older and being female, as well as having more years of education, previous working experience with the geriatric population, having higher interest in care of older people, and having more frequent social interaction with healthy older people (Leung et al. 2011). A recent systematic review of 25 studies across different countries, however, suggested that age and gender are not reliably associated with nurse's attitudes toward older patients, whereas preference to work with older patients and level of knowledge related to ageing are more consistent predictors (Liu et al. 2013). These same two factors, along with high anxiety about one's own ageing, were the strongest predictors of negative attitudes toward ageing among nurses (Liu et al. 2015). Further, in a sample of junior doctors in Singapore, personal and professional background characteristics such as age, marital status, living arrangements and years in medical practice were not associated with attitudes 
towards older adults (Lui and Wong 2009). Harries and colleagues (Harries et al. 2007) found no effect of medical specialty on attitudes and clinical decision making in response to patient vignettes. However, other researchers report such differences, e.g. that surgeons tend to hold more negative attitudes toward ageing compared to other medical subspecialties (Krain et al. 2007). Taken together, the available evidence on health care provider characteristics which may serve as predictors of age bias is mixed and inconclusive, and further research in this area is warranted.

Factors Associated with the Older Patient Some characteristics of the older patient may increase the likelihood that negative age stereotypes are activated and that age-based discrimination can occur. We will first address how older patients' health and functional status may influence attitudes toward ageing, and then discuss the concept of "self-ageism" and its impact on health and health care.

Past research on patient factors in ageism, which has been primarily conducted among mental health providers, spawned the term "healthism" to describe negative perceptions of others based on poor health status, not purely on age (Gekoski and Knox 1990; James and Haley 1995). Because poor health is strongly associated with old age and older adult identity (Coupland and Coupland 1994; Vauclair et al. 2015), the potential impact of "healthism" on the quality of patient-provider interactions and on care in the health care system is worthy of brief discussion. (Bodner et al. 2018, Chap. 15 provide additional details on this construct in their chapter on ageism in the mental health care setting, in this volume.)

Health care providers may develop attitudes toward older patients based on their medical diagnoses, functional deficits, or symptoms. A bias against older adults who are medically ill was demonstrated in a sample of mental health therapists (James and Haley 1995). Among medical providers, Gunderson and colleagues (Gunderson et al. 2005) found that rurally-based physicians in the U.S. endorsed more negative views of "nursing home patients" compared to typical "older" patients, in terms of patients' ability to change health behaviors and to learn new health-related information, their ability to offer important input during a medical visit, and their personality traits (e.g., "less warm and accepting"). Healthism may be related to the increasing "medicalization" of old age in Western societies identified by some scholars (Ng et al. 2015). Increased focus on the medical aspects of being old - to the exclusion of other dimensions of older age - is reflected at the level of policy and reimbursement in the geriatric health care setting, and has a clear impact on provider choices, service availability, and quality of care (Binney et al. 1990). A recent sociological study of changes in culture-based age stereotypes appearing in print over the past 200 years in the USA found an increasing association over time between the mention of an older adult and references to the medical status of that person, using words such as "sickness" or "stamina" (Ng et al. 2015). This increasing medicalization of old age was associated with increasingly negative age stereotypes, leading the authors to conclude that this increasing negativity toward older adults is systemic and pervasive throughout the culture. 
The construct of healthism may be related to self-ageism (see below). In an effort to distance themselves from stereotypical views of old age and their own aging experience, older adults may tend to deny health problems to order to more easily present as exemplifying "healthy ageing" (Tanner 2003).

\subsubsection{Self-Ageism in the Health Care Setting}

Ageist biases or assumptions held by older adults themselves (i.e. "self-ageism") may also impact their interactions with the medical system and quality of health care. Among older adults, the development of negative attitudes toward ageing or older people can be considerable, and in fact may be inevitable in an ageist society (Levy 2001). These biases may lead to irrational illness perceptions, for example, that pain and suffering are to be expected in old age. One recent qualitative study on back pain - one of the most common medical conditions among older adults around the globe - found that many older patients believe that pain is a "normal" part of old age (Makris et al. 2015). They are less likely to seek treatment for unmet medical needs, due to low expectancies of being helped because of their advanced age (Walters et al. 2001). These self-directed biases can also impact health and healthcare outcomes for the geriatric patient. Over a series of studies, Levy and colleagues have demonstrated a relationship between negative age self-stereotypes and health outcomes (Hausdorff et al. 1999; Levy and Banaji 2002). For example, one longitudinal study found that the endorsement of negative statements about older adults (e.g., "old people are helpless") was related to a higher risk for cardiovascular events over the next 38 years, controlling for cardiovascular risk factors (Levy et al. 2009). A more recent report revealed an association between negative age stereotypes held earlier in life and a later increased risk for Alzheimer's brain pathology (Levy et al. 2016). Moreover, a meta-analysis of 19 longitudinal studies concluded that positive subjective ageing (defined as positive ageing attitudes and youthful identities) contributes to better health and increased longevity in later life (Westerhof et al. 2014). Potential explanations may include that self-ageist ideas or negative views on ageing make it less likely for older adults to embrace positive health behaviors such as physical activity (Wurm et al. 2010), take preventive health measures, or adhere to recommended treatments (Levy and Myers 2004).

In summary, there is evidence of age-based bias at the micro, or interpersonal, level. This is reflected in attitudes and behaviors toward older adults among health care workers, and research suggests that these attitudes affect clinician behavior and clinical decision making. Patient factors, such as self-ageism, also impact the processes and outcomes of health care. Thus far, data regarding specific provider or patient factors which may predict prejudice and discrimination based on age in the health care setting appear to be mixed. In the next section, we examine ageism at the macro-level within this setting. 


\subsection{Structural Factors that Impact Care for Older Persons: Ageism at the Macro Level}

Macro-level ageism refers to age-biased attitudes and practices present at the cultural and institutional levels. This form of ageism has an important impact on health care for older adults. Numerous scholars have acknowledged the impact of age discrimination on continued inequalities in the health care system. Atul Gawande, in his recent popular book "Being Mortal," argues that despite the world-wide demographic changes resulting in an unprecedented number of older adults in the population - due in part to improvements in health care services - "...medicine has been slow to confront the very changes it has been responsible for - or to apply the knowledge we have about how to make old age better" (Gawande 2014, p. 34). He goes on to opine that health care consumers and policy makers "have not insisted on a change in priorities [in the health care system] ... when the prevailing fantasy is that we can be ageless, the geriatrician's uncomfortable demand is that we are not" (p. 46). As Prince et al. (2015) note, "the fitness for purpose of health services and systems for older adults and their complex, interacting, chronic medical and social difficulties is open to question" (p. 557).

There is general agreement that age discrimination is present in the systems and policies of health care services, though conclusive data on health care access for older persons in Europe is generally lacking (European Commission 2008). Highlighting the impact of cultural and institutional tradition on health care practice, a 2001 United Kingdom Department of Health publication noted that "...too often the financial commitment to older people in these core public services has not been translated into a cultural and institutional focus on the needs of older people....Instances of adverse discrimination have usually been inadvertent, a result of the survival of old systems and practices [emphasis added] that have failed to keep pace with changing attitudes or advances in the capacity of professionals to intervene successfully" (United Kingdom Department of Health 2001). This section will briefly review systemic and policy issues which demonstrate the existence of "institutional" or "structural" ageism (AGE Platform Europe 2016; International Longevity Center 2006) within health care.

\subsubsection{Age Discrimination Exists in the Health Care System}

Complaints of age bias in care, beyond the level of provider attitudes or providerlevel behaviors, have been reported within a variety of health care systems (European Commission 2008; International Longevity Center 2006; Jacobsen 2015; Williams 2009). A recent European Union-commissioned study across several EU countries reported that the frail, medically complex older adults comprise one of the populations at risk of "falling through [the] safety net" of public health care coverage programmes, resulting in reduced access to quality health care (European Commission 2008). This study found evidence, across most nations examined, of 
less access to necessary medical care among older adults compared to younger adults. Multiple so-called "supply-side" or system-level barriers to health care access for older adults were identified. These included requirements for patientborne cost sharing of services and medications, which can result in a deleterious interaction between older adults' higher service needs and more limited financial resources; geographic barriers and lack of transportation options, resulting in limited access to care due to mobility restrictions; inadequate numbers of geriatricstrained providers; a shortage of preventive and rehabilitation-focused care options for older patients; and age-discriminatory clinical decision making by providers. "Demand-side" or patient-level factors contributing to health disparities for older EU citizens include lower expectations of health care services, leading to minimal demand for change; more limited health literacy; and heightened challenges in managing their own care within a bureaucratic, fragmented service organization (European Commission 2008). As others have noted (Nies and Berman 2004), despite the fact that care coordination has long been identified as a quintessential pillar of quality geriatric care, current geriatric health care systems in the EU are generally not based on principles of collaborative partnership with social care systems and informal caregivers.

Access to care following a stroke, or cardiovascular accident (CVA), is one example that has been studied by researchers. In general, age-based bias in stroke treatment - referring to differences in care that are not justified by clinical evidence or best-practice guidelines - appears to be quite common, according to a recent systematic review (Luker et al. 2011). One study found a significant impact of age of the patient on the quality and type of immediate care for CVA in several UK countries, with older persons less likely to receive care consistent with current guidelines (Rudd et al. 2007). Another large pan-European study found that while older stroke patients have equal or better access to specialized stroke care, rates of standard diagnostic and therapeutic procedures, as well as rehabilitation services, were lower for older patients compared to their younger counterparts (Bhalla et al. 2004). These results are concerning in light of data that suggest that health outcomes after stroke do not vary by age when guideline-level care is provided (Saposnik et al. 2009). Of note, it is likely that the age-based differences identified in these studies represent the interaction of micro-level age-based attitudes (such as clinician decisions or patient preferences) and institutional or cultural norms in stroke care. However, clear instances of age-related bias in formal policy regarding stroke care can be found in a number of countries. For example, Greece has a policy governing decisions in inpatient stroke care, with patients over 65 sent for admission to a general internal medicine ward rather than a neurology specialty service (Theofanidis 2015). In Finland, a recently revamped policy does not provide coverage for medical rehabilitation - services to address deficits in activities of daily living following an illness - for persons over age 65 (AGE Platform Europe 2016), despite functional rehabilitation being part of standard care for many patients with stroke.

How health care services are reimbursed can differently affect older adults compared to younger patients. Health care reimbursement is a topic of great interest currently, as policy makers in many different countries work to address anticipated 
budget shortfalls due to ageing populations. As others have noted, current payment mechanisms incentivize medical procedures and technology-driven tests, but do not reimburse providers for the often complicated and time-consuming process of geriatric care (Alliance for Aging Research 2002). In addition, in many publicly-funded health care systems, there is an ongoing and heated debate about the rights of older persons to receive any health care benefits, and about how to manage the financial "burden" related to the care of older persons. Surveys within such countries reveal public opinion supporting the idea of an age cut-off for medical services; for example, in Belgium, persons over 85 years old are considered by many citizens as "not worthy of care" (AGE Platform Europe 2016). Within the UK's National Health Service, discussions about rationing of care have frequently pointed to long-standing age-based discrimination at a systemic level (Shaw 1994). For example, until recently, the UK's National Health Service breast cancer screening program offered regular mammography only to women under the age of 65 (the program has recently been extended up to age 70). A performance indicator in the United Kingdom sets the undesirable outcome "premature death" as occurring at or below age 75. Thus, this is a policy which does not differentiate patients based on comorbidities or clinical presentation, but on age alone. The policy also implies that human life after age 75 has less inherent worth compared to life at a younger age (AGE Platform Europe 2016). Vascular disease screening invitations in the UK are also age-based, despite the high prevalence of cardiovascular disease among older adults (Lievesley 2009). These are not isolated examples. Upper age limits on funding for diagnostic tests, screening procedures, and health-related social benefits are part of policy in many European countries (AGE Platform Europe 2016).

In the US, the existence of the federally funded and regulated Medicare health care insurance program for citizens over age 65 has resulted in a health care coverage system for older adults that is effectively separate from coverage programs for other age groups. Medicare policies on reimbursement for medications, equipment, and services have a profound and wide-reaching effect on health care for older adults in the US. One example is Medicare's payment policy for inpatient rehabilitation, usually provided within a long-term care setting. Current Medicare benefits provide for a maximum of 100 days of reimbursement, creating an incentive for facilities to keep patients in the rehabilitation setting for this full time period, whether or not the patient is benefitting from the care or able to participate in rehabilitation treatments such as physical therapy. Medicare reimbursement policies are not structured to provide incentives to delay or prevent entry into a long-term care facility. There was no coverage for preventive care until recently, and preventive services that would benefit a majority of older adults (and reduce health care costs), such as a falls risk screening or home safety assessment, are still excluded. Medicare neither reimburses comprehensive outpatient geriatric care, despite evidence of good outcomes (Boult et al. 2001), nor the relatively low costs of part-time custodial care at home (e.g., assistance with cooking, cleaning, shopping, bathing) to keep frail patients safe and functioning outside of an institution. Of note, until recently, Medicare did not provide reimbursement for care costs incurred during participation in clinical research trials. 
It should be noted that changes in the US public health care programs are gradually occurring as the Patient Protection and Affordable Care Act (ACA) of 2010 continues implementation, and there may be additional positive impacts on health care services for older adults (Goyal et al. 2012). The ACA includes a mandate for the expansion of the scope of routine care to include mental health care and chronic disease self-management, and places an emphasis on a patient-centered care experience and quality of life as measurable outcomes. Financial payment incentives are being realigned, especially for primary care providers who work in geriatrics, and there is increased attention to the development of care coordination and disease management programs for older adults to prevent unnecessary medical interventions and reduce costs. Thus, there may be reduction of age bias at the systemic level as we move toward the future.

\subsubsection{Older Persons Participate Minimally in Clinical Trials}

Another aspect of age bias at the structural level concerns clinical research trial participation. As Topinkova and colleagues note (Topinkova et al. 2012), "the health care industry and regulatory authorities have for a long time negated the age-specific needs of older drug consumers. Only recently the European Medicines Agency has begun recognizing the need for a specific 'geriatric' approach in both drug development and registration" (p. 479). Older patients are typically excluded from the development and testing of new compounds, from ongoing drug efficacy monitoring programs, and from undergoing age-appropriate outcome evaluations. In clinical drug trials for cancer and coronary artery disease, both conditions for which incidence increases with age, persons over the age of 65 are systematically underrepresented (Witham and McMurdo 2007). The same trend can be seen in research on intervention for strokes and on stroke rehabilitation: in both cases, there is global evidence of age bias, as the mean age of participants in clinical trials reported in the stroke literature was a decade younger than the average age of stroke patients (Gaynor et al. 2014; Hadbavna and O'Neill 2013).

A systematic review of recruitment of older cancer patients into clinical trials identified age-related barriers to equal inclusion in four broad domains: trial design, physician factors, patient factors, and trial logistics (Townsley et al. 2005). In the majority of clinical trials, protocol design stipulates exclusion criteria such as impaired functional status, past cancer illnesses, and medical comorbidities. This effectively screens out many older patients. Indeed, in a recent prospective study, not being eligible was the most common reason for lower enrollment of older persons (Javid et al. 2012). Further, a recent study of heart failure trials (Cherubini et al. 2011) found that almost $50 \%$ of the trials included what the authors termed "poorly justified" exclusionary criteria, resulting in lower participation by patients over 65 years old. At least one study has found similar age-based bias in nonpharmacological health behavior clinical research (Levy et al. 2006).

Physician-related barriers to referral of older adults to clinical trials include provider concerns about co-morbidities and potential adverse events related to study 
participation, factors which are evaluated in the context of patient age (Townsley et al. 2005). There is no evidence that provider characteristics impact referral rates. A U.S. study compared rates of physicians offering clinical trial participation to older versus younger breast cancer patients, and found no significant associations with physician demographic or professional experience variables. Patient age and stage of disease were the only significant predictors of referral (Kemeny et al. 2003). In terms of patient-level barriers, both older and younger patients most frequently explained their nonparticipation in trials by a reluctance to experience limitations on their choice of treatment. Some scholars, however, assert that older adults' health literacy and knowledge about participation in clinical trials may be at a lower level compared to younger persons, preventing fully informed decision-making in these situations (Townsley et al. 2005).

Factors related to patient safety and scientific integrity, such as risk of adverse events and ensuring sample homogeneity, are often cited for this age-based exclusion. These are important concerns. However, the nonparticipation of older patients in clinical trials likely has a profound impact on health care for older adults. Lack of older adults' participation prevents the generalization of study results to older patients and therefore may contribute to "double discrimination": without clinical evidence supporting the use of novel treatments in the older population, the chance is reduced that older patients will receive these treatments. This may happen due to age-biased beliefs that continue unchallenged without newly emerging research on older populations, or due to clinicians' uncertainty about safety and benefits for older patients and a resultant reluctance to pursue screening or treatment (Walter et al. 2005). Thus, age-based barriers to access to medical therapy might be partially attributed to the under-representation of the older age population in clinical trials. Further, the treatments that older adults receive should be based on solid clinical evidence relevant to that population, which is not currently the case (Cherubini et al. 2011). Indeed, it can be argued that underrepresentation of the older patient population in clinical trials is not only one of the consequences of ageism in medicine, but may also be one of its major perpetuating factors.

\subsubsection{Training of Health Care Professionals}

Another systemic factor which may sustain the age bias which exists within the health care system is the type of training received by health care professionals. Several scholars have argued that training programs do too little to actively combat existing negative views of older adults and to positively promote geriatrics or gerontology as practice fields. Some years ago, Levenson (1981) asserted that "medical students' attitudes have reflected a prejudice against older persons surpassed only by their racial prejudice" (p. 161). More recent research has demonstrated that medical residents perceive themselves to have a gap in geriatric training and exposure to older patients (Chodosh et al. 1999), and that both US and European nursing students and nurses viewed the care of older people as a topic that currently receives 
too little attention in professional education programs (Kydd et al. 2014). Of note, however, a recent study of US medical schools reported improvements in the past decade in geriatric-specific physician training (Bragg et al. 2012). Thus, while inadequate training in geriatrics remains a problem to solve, it appears that institutions charged with health care education may be progressing in the right direction.

\subsection{Conclusions and Recommendations}

Health care represents a key domain of civilized life, and provides services to all members in a society. Indeed, bioethics scholars debating about the rationing of health care to address rising costs have argued that protecting health is of "special moral importance", also noting that health care systems are not prepared to meet the challenges of the ageing of the global population (Daniels 2013). There is ample research evidence demonstrating that age-based discrimination is common and long-standing among health care providers, within health care systems, and in health care policies. Further, there are systemic forces which have an impact on geriatric health services before the older patient even feels the need to seek care for example, the lengthy process of developing, testing, and monitoring medications, which has excluded older adults to a significant extent. On the positive side, there is increasing recognition of these manifestations of ageism at all levels, and there is increasing support for interventions to change negative attitudes and reduce age discrimination. The landscape of health care is not static. This may be especially true in the area of geriatrics, as countries around the globe scramble to prepare for the ever-increasing numbers of complex older patients.

An important additional point is this: given the complexities of health care, it is sometimes difficult to distinguish between inappropriate and discriminatory agebased bias - "ageism" - and prudent, carefully reasoned decisions by clinicians in their care of older adults. Multiple patient-level and institutional-level factors impact clinical decision-making about screening, diagnostic tests, and treatment (e.g., Breslau et al. 2016). Clinical decision-making for older patients is often a highly complex task which is not made easier with the dearth of clinical evidence regarding appropriate treatments for this population. Clinical practice is guided by familiarity and routine as well as evidence, and some categorizing or stereotyping of patients by risk or potential outcome is sometimes necessary to make treatment decisions. One might ask: how much of "ageism" in clinicians can be attributed to the perpetuation of outdated ideas regarding good clinical care for older adults, rather than purely to age-biased attitudes and behaviors? Is age bias merely reflective of our human affinity for tradition and resistance to change? This begs the question, however, of why health care systems have been so very resistant to change and slow to embrace proven approaches to improve services for this large group of constituents. Older adults comprise the most frequently seen, and costliest, consumer group in health care. Their numbers are increasing. Yet, there is a pronounced lag in the development of widespread implementation of well-accepted clinical guidelines 
for this population, despite adequate evidence documenting the benefits (Boult et al. 2001). Do ageist stereotypes and prejudices - in the provider, in the patient, in the system - play a role? We believe they do. Thus, while we acknowledge that agebased bias may not always be specifically reflective of negative age stereotyping, we believe ageism remains a powerful force within the health care setting. Identifying ageist attitudes and practices is the first step to eliminating this bias and improving health care for persons of all ages.

The task remains to define and describe health care for older adults that is not ageist. What does this look like? We believe that a non-ageist approach to developing health care services for older persons does not mean standardizing assessment and treatment procedures and processes across the age span. We, like other authors (Bodner et al. 2018, Chap. 15, this volume), believe that health care equity for older adults refers to equality in the adequacy and case-appropriateness of diagnosis and treatment, rather than to uniformity in the evaluation and treatment itself. It means creating care that respects the unique needs of the aged, that results in high patient satisfaction, and that achieves success in reaching desired outcomes. High quality medical treatment is always relative to what is required and what is adequate for that particular patient. It requires an individualized, person-centered approach to care (Breslau et al. 2016), and is in keeping with the anti-ageist ideology inherent in the principles of modern geriatric practice (Coupland and Coupland 1994). It supports the potential for the field of geriatric medicine not only to treat health conditions and reduce suffering in older persons, but also to "engage in work either to endorse or to reconstruct patients' [ageist] conceptions of their own ageing and health" (Coupland and Coupland 1994). It is our view that the health care system has an obligation to actively address ageism - in patients, in the professionals working within the system, and in the systems themselves.

In conclusion, the health care system can be improved for patients and health care providers alike through acknowledging and working to eliminate ageism. To this end, continued research in this area is certainly needed. Future research efforts should strive be more theoretically-based, and might focus on further uncovering factors that influence the development and maintenance of age discrimination in this setting. Hagestad and Uhlenberg (2005) argue that micro-level bias results in macro-level bias through the isolation of social sub-groups and subsequent reduced inter-group contact. Social networks - the meso-level at which ageism can be manifested - may be an important area for future research and intervention to address ageism in the health care setting. Certainly, improved education and training of the key players at all levels of geriatric health care is vital to reducing age bias. This includes hospital administrators, physicians, nurses, personal caregivers, and associated health professions. Acknowledging and working to reduce ageist attitudes in patients and their family caregivers cannot be neglected in these efforts, as ample evidence points to the important impact of self-directed ageism on health. We can take a cue from best-practice geriatric health care: these efforts need to be coordinated and collaborative, taking into account all sources and factors of age bias and discrimination, in order to address this problem. As stated quite succinctly by the physician who coined the term "ageism," Robert Butler: "ultimately, such initiatives will benefit all who would grow old" (Butler 2009). That means all of us. 


\section{References}

AGE Platform Europe. (2016). AGE Platform Europe Position on Structural Ageism. http://ageplatform.eu/images/stories/Publications/papers/AGE_IntergenerationalSolidarity_Position_ on_Structural_Ageism.pdf

Alliance for Aging Research. (2002). Medical never-never land: Ten reasons why America isn't ready for the coming age boom. Washington, DC: Alliance for Aging Research.

Ambady, N. (2002). Physical therapists' nonverbal communication predicts geriatric patients' health outcomes. Psychology and Aging, 17(3), 443.

Baltes, M. M., Burgess, R. L., \& Stewart, R. B. (1980). Independence and dependence in self-care behaviors in nursing home residents: An operant-observational study. International Journal of Behavioral Development, 3(4), 489-500.

Ben-Harush, A., Shiovitz-Ezra, S., Doron, I., Alon, S., Leibovitz, A., Golander, H., et al. (2016). Ageism among physicians, nurses, and social workers: Findings from a qualitative study. European Journal of Ageing, 14, 39. https://doi.org/10.1007/s10433-016-0389-9

Bhalla, A., Grieve, R., Tilling, K., Rudd, A. G., \& Wolfe, C. D. (2004). Older stroke patients in Europe: Stroke care and determinants of outcome. Age and Ageing, 33(6), 618-624.

Binney, E. A., Estes, C. L., \& Ingman, S. R. (1990). Medicalization, public policy and the elderly: Social services in jeopardy? Social Science \& Medicine, 30(7), 761-771.

Boswell, S. S. (2012). Predicting trainee ageism using knowledge, anxiety, compassion, and contact with older adults. Educational Gerontology, 38(11), 733-741.

Bodner, E., Palgi, Y., \& Wyman, F. (2018). Ageism in mental health assessment and treatment of older adults. In L. Ayalon \& C. Tesch-Römer (Eds.), Contemporary perspectives on ageism: Vol. 19. International perspectives on aging (pp. 241-262). Berlin: Springer.

Boult, C., Boult, L. B., Morishita, L., Dowd, B., Kane, R. L., \& Urdangarin, C. F. (2001). A randomized clinical trial of outpatient geriatric evaluation and management. Journal of the American Geriatrics Society, 49(4), 351-359.

Bowling, A. (1999). Ageism in cardiology. The BMJ, 319, 1353-1355.

Bragg, E. J., Warshaw, G. A., Meganathan, K., \& Brewer, D. E. (2012). The development of academic geriatric medicine in the United States 2005 to 2010: An essential resource for improving the medical care of older adults. Journal of the American Geriatrics Society, 60(8), 1540-1545.

Breslau, E., Gorin, S., Edwards, H., Schonberg, M., Saiontz, N., \& Walter, L. (2016). An individualized approach to cancer screening decisions in older adults: A multilevel framework. Journal of General Internal Medicine, 31(5), 539-547.

Butler, R. N. (1975). Psychiatry and the elderly: An overview. American Journal of Psychiatry, 132(9), 893-900.

Butler, R. N. (2009). Combating ageism. International Psychogeriatrics, 21, 211.

Buttigieg, S., Ilinca, S., Jose, M. S., \& Larsson, A. T. (2018). Researching ageism in health-care and long term care. In L. Ayalon \& C. Tesch-Römer (Eds.), Contemporary perspectives on ageism: Vol. 19. International perspectives on aging (pp. 491-513). Berlin: Springer.

Caris-Verhallen, W. M., de Gruijter, I. M., Kerkstra, A., \& Bensing, J. M. (1999). Factors related to nurse communication with elderly people. Journal of Advanced Nursing, 30(5), 1106-1117.

Cherubini, A., Oristrell, J., Pla, X., Ruggiero, C., Ferretti, R., Diestre, G., et al. (2011). The persistent exclusion of older patients from ongoing clinical trials regarding heart failure. Archives Internal Medicine, 171(6), 550-556.

Chodosh, J., Tulsky, A., Naumburg, E., Branca, L., Frankel, R. M., McCann, R. M., et al. (1999). What residents want to know about geriatrics: An approach to curriculum development. Gerontology \& Geriatrics Education, 20(2), 19-35.

Coupland, J., \& Coupland, N. (1994). Old age doesn't come alone': Discursive representations of health-in-aging in geriatric medicine. The International Journal of Aging \& Human Development, 39(1), 81-95.

Courtney, M., Tong, S., \& Walsh, A. (2000). Acute-care nurses' attitudes towards older patients: A literature review. International Journal of Nursing Practice, 6(2), 62-69.

Daniels, N. (2013). Global aging and the allocation of health care across the life span. American Journal of Bioethics, 13(8), 1-2. https://doi.org/10.1080/15265161.2013.807187 
European Commission. (2008). Quality in and equality of access to healthcare services. Retrieved from http://ec.europa.eu/social

Fialová, D., Kummer, I., Držaić, M., \& Leppee, M. (2018). Ageism in medication use in older patients. In L. Ayalon \& C. Tesch-Römer (Eds.), Contemporary perspectives on ageism: Vol. 19. International perspectives on aging (pp. 214-240). Berlin: Springer.

Gawande, A. (2014). Being mortal. London: Profile Books, Wellcome Collection.

Gaynor, E. J., Geoghegan, S. E., \& O’Neill, D. (2014). Ageism in stroke rehabilitation studies. Age and Ageing, 43(3), 429-431.

Gekoski, W. L., \& Knox, V. J. (1990). Ageism or healthism? Perceptions based on age and health status. Journal of Aging and Health, 2(1), 15-27.

Goyal, S., Kamel, M., \& Thomas-Hemak, L. (2012). Patient protection and affordable care act: Implications for geriatrics practice. http://www.todaysgeriatricmedicine.com/news/ ex_101912.shtml. Accessed 10 Apr 2016.

Greenberg, J., Schimel, J., \& Martens, A. (2002). Ageism: Denying the face of the future. In T. D. Nelson (Ed.), Ageism: Stereotyping and prejudice against older persons (pp. 27-48). Cambridge, MA: The MIT Press.

Greene, M. D., Adelman, R. D., \& Rizzo, C. (1996). Problems in communication between physicians and older patients. Journal of Geriatric Psychiatry, 29(1), 13-32.

Gunderson, A., Tomkowiak, J., Menachemi, N., \& Brooks, R. (2005). Rural physicians' attitudes toward the elderly: Evidence of ageism? Quality Management in Health Care, 14(3), 167-176.

Hadbavna, A., \& O'Neill, D. (2013). Ageism in interventional stroke studies. Journal of the American Geriatrics Society, 61(11), 2054-2055.

Hagestad, G., \& Uhlenberg, P. (2005). The social separation of old and young: A root of ageism. Journal of Social Issues, 61(2), 343-360.

Haigney, E., Morgan, R., King, D., \& Spencer, B. (1997). Breast examinations in older women: Questionnaire survey of attitudes of patients and doctors. The BMJ, 315(7115), 1058-1059.

Harries, C., Forrest, D., Harvey, N., McClelland, A., \& Bowling, A. (2007). Which doctors are influenced by a patient's age? A multi-method study of angina treatment in general practice, cardiology and gerontology. Quality \& Safety in Health Care, 16(1), 23-27.

Hausdorff, J. M., Levy, B. R., \& Wei, J. Y. (1999). The power of ageism on physical function of older persons: Reversibility of age-related gait changes. Journal of the American Geriatrics Society, 47(11), 1346-1349.

Hayes, L. J., Orchard, C. A., McGillis Hall, L., Nincic, V., O’Brien-Pallas, L., \& Andrews, G. (2006). Career intentions of nursing students and new nurse graduates: A review of the literature. International Journal of Nursing Education Scholarship, 3(1), Article26. https://doi. org/10.2202/1548-923x.1281

Institute of Medicine. (2008). Retooling for an aging America: Building the health care workforce. Washington, DC: National Academies Press.

International Longevity Center. (2006). Ageism in America. New York: International Longevity Center.

Iversen, T. N., Larsen, L., \& Solem, P. E. (2009). A conceptual analysis of ageism. Nordic Psychology, 61(3), 4-22. https://doi.org/10.1027/1901-2276.61.3.4

Jacobsen, F. F. (2015). Understanding public elderly care policy in Norway: A narrative analysis of governmental white papers. Journal of Aging Studies, 34, 199-205.

James, J. W., \& Haley, W. E. (1995). Age and health bias in practicing clinical psychologists. Psychology and Aging, 10(4), 610-616.

Javid, S. H., Unger, J. M., Gralow, J. R., Moinpour, C. M., Wozniak, A. J., Goodwin, J. W., et al. (2012). A prospective analysis of the influence of older age on physician and patient decisionmaking when considering enrollment in breast cancer clinical trials (SWOG S0316). The Oncologist, 17(9), 1180-1190.

Jecker, N. S. (2013). Justice between age groups: An objection to the prudential lifespan approach. American Journal of Bioethics, 13(8), 3-15. https://doi.org/10.1080/15265161.2013.802061

Kagan, S. H. (2008). Ageism in cancer care. Seminars in Oncology Nursing, 24(4), 246-253.

Kearney, N., Miller, M., Paul, J., \& Smith, K. (2000). Oncology healthcare professionals' attitudes toward elderly people. Annals of Oncology, 11(5), 599-601. 
Kemeny, M. M., Peterson, B. L., Kornblith, A. B., Muss, H. B., Wheeler, J., Levine, E., et al. (2003). Barriers to clinical trial participation by older women with breast cancer. Journal of Clinical Oncology, 21(12), 2268-2275.

Konig, H. H., Leicht, H., Bickel, H., Fuchs, A., Gensichen, J., Maier, W., et al. (2013). Effects of multiple chronic conditions on health care costs: An analysis based on an advanced tree-based regression model. BMC Health Services Research, 13, 219. https://doi. org/10.1186/1472-6963-13-219

Krain, L. P., Fitzgerald, J. T., Halter, J. B., \& Williams, B. C. (2007). Geriatrics attitudes and knowledge among surgical and medical subspecialty house officers. Journal of the American Geriatrics Society, 55(12), 2056-2060.

Kuhlmey, A., Winter, M. H., Maaz, A., Hofmann, W., Nordheim, J., \& Borchert, C. (2003). High utilization of health care services by older adults. Zeitschrift für Gerontologie und Geriatrie, 36(3), 233-240.

Kydd, A., Touhy, T., Newman, D., Fagerberg, I., \& Engstrom, G. (2014). Attitudes towards caring for older people in Scotland, Sweden and the United States. Nursing Older People, 26(2), 33-40. https://doi.org/10.7748/nop2014.02.26.2.33.e547

Lambrinou, E., Sourtzi, P., Kalokerinou, A., \& Lemonidou, C. (2009). Attitudes and knowledge of the Greek nursing students towards older people. Nurse Education Today, 29(6), 617-622.

Lehnert, T., Heider, D., Leicht, H., Heinrich, S., Corrieri, S., Luppa, M., et al. (2011). Review: Health care utilization and costs of elderly persons with multiple chronic conditions. Medical Care Research and Review, 68(4), 387-420.

Leung, S., Logiudice, D., Schwarz, J., \& Brand, C. (2011). Hospital doctors' attitudes towards older people. Internal Medicine Journal, 41(4), 308-314.

Levenson, A. J. (1981). Ageism: A major deterrent to the introduction of curricula in aging. Gerontology \& Geriatrics Education, 1(3), 161-162.

Levy, B. R. (2001). Eradication of ageism requires addressing the enemy within. The Gerontologist, $41(5), 578-579$.

Levy, B. R., \& Banaji, M. R. (2002). Implicit ageism. In T. D. Nelson (Ed.), Ageism: Stereotyping and prejudice against older persons (pp. 49-75). Cambridge, MA: The MIT Press.

Levy, B. R., \& Myers, L. M. (2004). Preventive health behaviors influenced by self-perceptions of aging. Preventive Medicine, 39(3), 625-629.

Levy, B. R., Kosteas, J., Slade, M., \& Myers, L. (2006). Exclusion of elderly persons from healthrisk behavior clinical trials. Preventive Medicine, 43(2), 80-85.

Levy, B. R., Zonderman, A. B., Slade, M. D., \& Ferrucci, L. (2009). Age stereotypes held earlier in life predict cardiovascular events in later life. Psychological Science, 20(3), 296-298.

Levy, B. R., Ferrucci, L., Zonderman, A. B., Slade, M. D., Troncoso, J., \& Resnick, S. M. (2016). A culture-brain link: Negative age stereotypes predict Alzheimer's disease biomarkers. Psychology and Aging, 31(1), 82-88.

Lievesley, N. (2009). Ageism and age discrimination in secondary health care in the United Kingdom: A review from the literature. London: Centre for Policy on Aging Department of Health.

Liu, Y. E., While, A. E., Norman, I. J., \& Ye, W. (2012). Health professionals' attitudes toward older people and older patients: A systematic review. Journal of Interprofessional Care, 26(5), 397-409. https://doi.org/10.3109/13561820.2012.702146

Liu, Y. E., Norman, I. J., \& While, A. E. (2013). Nurses' attitudes towards older people: A systematic review. International Journal of Nursing Studies, 50(9), 1271-1282. https://doi. org/10.1016/j.ijnurstu.2012.11.021

Liu, Y. E., Norman, I. J., \& While, A. E. (2015). Nurses' attitudes towards older people and working with older patients: An explanatory model. Journal of Nursing Management, 23(8), 965973. https://doi.org/10.1111/jonm.12242

Lookinland, S., \& Anson, K. (1995). Perpetuation of ageist attitudes among present and future health care personnel: Implications for elder care. Journal of Advanced Nursing, 21(1), 47-56.

Lui, N. L., \& Wong, C. H. (2009). Junior doctors' attitudes towards older adults and its correlates in a tertiary-care public hospital. Annals, Academy of Medicine, Singapore, 38(2), 125-129.

Luker, J. A., Wall, K., Bernhardt, J., Edwards, I., \& Grimmer-Somers, K. A. (2011). Patients' age as a determinant of care received following acute stroke: A systematic review. BMC Health Services Research, 11. https://doi.org/10.1186/1472-6963-11-161 
Madan, A. K., Aliabadi-Wahle, S., \& Beech, D. J. (2001). Ageism in medical students' treatment recommendations: The example of breast-conserving procedures. Academic Medicine, 76(3), 282-284.

Madan, A. K., Cooper, L., Gratzer, A., \& Beech, D. J. (2006). Ageism in breast cancer surgical options by medical students. Tennessee Medicine, 99(5), 37-38. 41.

Makris, U. E., Higashi, R. T., Marks, E. G., Fraenkel, L., Sale, J. E., Gill, T. M., \& Reid, M. C. (2015). Ageism, negative attitudes, and competing co-morbidities--why older adults may not seek care for restricting back pain: A qualitative study. BMC Geriatrics, 15, 39. https://doi. org/10.1186/s12877-015-0042-z

Martens, A., Goldenberg, J. L., \& Greenberg, J. (2005). A terror management perspective on ageism. Journal of Social Issues, 61(2), 223-239.

McLafferty, I., \& Morrison, F. (2004). Attitudes towards hospitalized older adults. Journal of Advanced Nursing, 47(4), 446-453.

McLaughlin, T. J., Soumerai, S. B., Willison, D. J., Gurwitz, J. H., Borbas, C., Guadagnoli, E., et al. (1996). Adherence to national guidelines for drug treatment of suspected acute myocardial infarction: Evidence for undertreatment in women and the elderly. Archives of Internal Medicine, 156(7), 799-805.

Meisner, B. A. (2012). Physicians' attitudes toward aging, the aged, and the provision of geriatric care: A systematic narrative review. Critical Public Health, 22(1), 61-72. https://doi.org/10.1 080/09581596.2010.539592

Nelson, T. D. (2005). Ageism: Prejudice against our feared future self. Journal of Social Issues, 61(2), 207-221.

Ng, R., Allore, H. G., Trentalange, M., Monin, J. K., \& Levy, B. R. (2015). Increasing negativity of age stereotypes across 200 years: Evidence from a database of 400 million words. PLoS One, 10(2), e0117086. https://doi.org/10.1371/journal.pone.0117086

Nies, H., \& Berman, P. (2004). Integrating services for older people: A resource book for managers. Dublin: European Health Management Association.

Nussbaum, J. F., Pitts, M. J., Huber, F. N., Krieger, J. L. R., \& Ohs, J. E. (2005). Ageism and ageist language across the life span: Intimate relationships and non-intimate interactions. Journal of Social Issues, 61(2), 287-305.

Palmore, E. (1990). Ageism: Negative and positive. New York: Springer.

Palmore, E. (2001). The ageism survey: First findings. The Gerontologist, 41(5), 572-575.

Peake, M. D., Thompson, S., Lowe, D., \& Pearson, M. G. (2003). Ageism in the management of lung cancer. Age and Ageing, 32(2), 171-177.

Prince, M. J., Wu, F., Guo, Y., Gutierrez Robledo, L. M., O’Donnell, M., Sullivan, R., \& Yusuf, S. (2015). The burden of disease in older people and implications for health policy and practice. Lancet, 385(9967), 549-562. https://doi.org/10.1016/s0140-6736(14)61347-7

Robb, C., Chen, H., \& Haley, W. E. (2002). Ageism in mental health and health care: A critical review. Journal of Clinical Geropsychology, 8(1), 1-12.

Rudd, A. G., Hoffman, A., Down, C., Pearson, M., \& Lowe, D. (2007). Access to stroke care in England, Wales and Northern Ireland: The effect of age, gender and weekend admission. Age and Ageing, 36(3), 247-255.

Saposnik, G., Kapral, M. K., Coutts, S. B., Fang, J., Demchuk, A. M., \& Hill, M. D. (2009). Do all age groups benefit from organized inpatient stroke care? Stroke, 40(10), 3321-3327.

Shaw, A. B. (1994). In defence of ageism. Journal of Medical Ethics, 20(3), 188-191, 194.

Snyder, M., \& Miene, P. K. (1994). Stereotyping of the elderly: A functional approach. British Journal of Social Psychology, 33(1), 63-82.

Soderhamn, O., Lindencrona, C., \& Gustavsson, S. M. (2001). Attitudes toward older people among nursing students and registered nurses in Sweden. Nurse Education Today, 21(3), 225 229. https://doi.org/10.1054/nedt.2000.0546

Tanner, D. (2003). Older people and access to care. British Journal of Social Work, 33(4), 499-515.

Theofanidis, D. (2015). A qualitative study on discrimination and ethical implications in stroke care in contemporary Greece. Journal of Vascular Nursing, 33(4), 138-142. https://doi. org/10.1016/j.jvn.2015.05.040 
Thiem, U., Hinrichs, T., Muller, C. A., Holt-Noreiks, S., Nagl, A., Bucchi, C., et al. (2011). Prerequisites for a new health care model for elderly people with multiple morbidities: Results and conclusions from 3 years of research in the PRISCUS consortium. Zeitschrift für Gerontologie und Geriatrie, 44(Suppl 2), 101-112. https://doi.org/10.1007/s00391-011-0246-6

Topinkova, E., Baeyens, J. P., Michel, J. P., \& Lang, P. O. (2012). Evidence-based strategies for the optimization of pharmacotherapy in older people. Drugs \& Aging, 29(6), 477-494. https://doi. org/10.2165/11632400-000000000-00000

Townsley, C. A., Selby, R., \& Siu, L. L. (2005). Systematic review of barriers to the recruitment of older patients with cancer onto clinical trials. Journal of Clinical Oncology, 23(13), 31123124. https://doi.org/10.1200/jco.2005.00.141

United Kingdom Department of Health. (2001). National service framework for older people. London: Department of Health.

Vauclair, C. M., Marques, S., Lima, M. L., Abrams, D., Swift, H., \& Bratt, C. (2015). Perceived age discrimination as a mediator of the association between income inequality and older people's self-rated health in the European region. Journals of Gerontology, B: Psychological Sciences and Social Sciences, 70(6), 901-912.

Walter, L., Lewis, C., \& Barton, M. (2005). Screening for colorectal, breast, and cervical cancer in the elderly: A review of the evidence. The American Journal of Medicine, 118(10), 1078-1086.

Walters, K., Iliffe, S., \& Orrell, M. (2001). An exploration of help-seeking behaviour in older people with unmet needs. Family Practice, 18(3), 277-282.

Wells, Y., Foreman, P., Gething, L., \& Petralia, W. (2004). Nurses' attitudes toward aging and older adults--examining attitudes and practices among health services providers in Australia. Journal of Gerontological Nursing, 30(9), 5-13.

Wenger, N. K. (1997). Coronary heart disease: An older woman's major health risk. The BMJ, 315(7115), 1085-1090.

Westerhof, G. J., Miche, M., Brothers, A. F., Barrett, A. E., Diehl, M., Montepare, J. M., et al. (2014). The influence of subjective aging on health and longevity: A meta-analysis of longitudinal data. Psychology and Aging, 29(4), 793-802.

Williams, P. W. (2009). Age discrimination in the delivery of health care services to our elders. Marquette Elder's Advisor, 11(1). http://scholarship.law.marquette.edu/elders/vol11/iss1/3

Witham, M. D., \& McMurdo, M. E. (2007). How to get older people included in clinical studies. Drugs \& Aging, 24(3), 187-196.

World Health Organization. (2008). Global burden of disease: 2004 update. Geneva: World Health Organization.

Wurm, S., Tomasik, M. J., \& Tesch-Römer, C. (2010). On the importance of a positive view on ageing for physical exercise among middle-aged and older adults: Cross-sectional and longitudinal findings. Psychology \& Health, 25(1), 25-42. https://doi.org/10.1080/08870440802311314

Open Access This chapter is licensed under the terms of the Creative Commons Attribution 4.0 International License (http://creativecommons.org/licenses/by/4.0/), which permits use, sharing, adaptation, distribution and reproduction in any medium or format, as long as you give appropriate credit to the original author(s) and the source, provide a link to the Creative Commons license and indicate if changes were made.

The images or other third party material in this chapter are included in the chapter's Creative Commons license, unless indicated otherwise in a credit line to the material. If material is not included in the chapter's Creative Commons license and your intended use is not permitted by statutory regulation or exceeds the permitted use, you will need to obtain permission directly from the copyright holder.

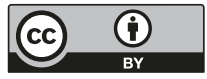

